LA-UR- 94-3373
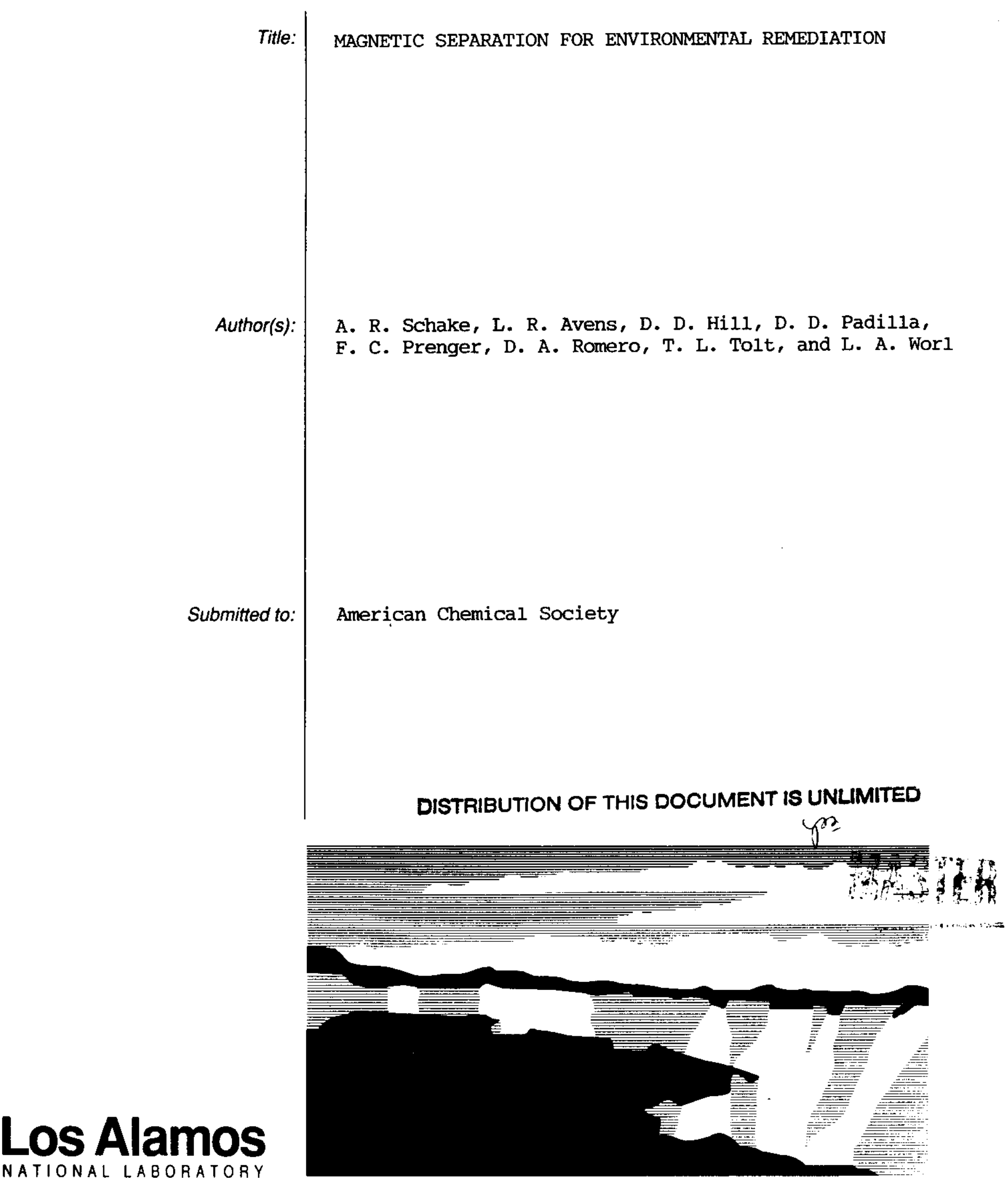

Los Alamos National Laboratory, an affirmative action/equal opportunity employer, is operated by the University of California for the U.S. Department of Energy under contract W.7405-ENG-36. By acceptance of this article, the publisher recognizes that the U.S. Government retains a nonexclusive, royalty-free license to publish or reproduce the published form of this contribution, or to allow others to do so, for U.S. Government purposes. The Los Alamos National Laboratory requests that the publisher identify this article as work performed under the auspices of the U.S. Department of Energy. 


\title{
MAGNETIC SEPARATION FOR ENVIRONMENTAL REMEDIATION
}

\author{
Ann R. Schake, ${ }^{1}$ Larry R. Avens, ${ }^{1}$ Dallas D. Hill, ${ }^{1}$ Dennis D. Padilla, ${ }^{1}$ F. \\ Coyne Prenger, ${ }^{1}$ David A. Romero, ${ }^{1}$ Thomas L. Tolt, ${ }^{2}$ and Laura A. Worl ${ }^{1}$ \\ ${ }^{1}$ Los Alamos National Laboratory, Los Alamos, NM 87545 \\ ${ }^{2}$ Lockheed Environmental Systems \& Technologies Company, \\ Las Vegas, NV 89119
}

\section{INTRODUCTION}

Magnetic separation is a physical separation process that segregates materials on the basis of magnetic susceptibility. High Gradient Magnetic Separation (HGMS) is a form of magnetic separation used to separate solids from other solids, liquids or gases. HGMS uses large magnetic field gradients to separate ferromagnetic and paramagnetic particles from diamagnetic host materials. The technology relies only on physical properties, and therefore separations can be achieved while producing a minimum of secondary waste.

Actinide and fission product wastes within the DOE weapons complex pose challenging problems for environmental remediation. Because the majority of actinide complexes and many fission products are paramagnetic, while most host materials are diamagnetic, HGMS can be used to concentrate the contaminants into a low volume waste stream. We are currently developing HGMS for applications to soil decontamination, liquid waste treatment, underground storage tank waste treatment, and actinide chemical processing residue concentration. ${ }^{1}$ In 1992 Los Alamos National Laboratory entered into a Cooperative Research and Development Agreement (CRADA) with Lockheed Environmental Systems \& Technologies Company to develop High Gradient Magnetic Separation technology for soil decontamination.

Application of HGMS usually involves passing a slurry of the contaminated mixture through a magnetized volume. A diagram of the method is shown in Figure 1. Field gradients are produced in the magnetized volume by a ferromagnetic matrix material, such as steel wool, expanded metal, iron shot, or nickel foam. The matrix fibers become trapping sites for ferromagnetic and paramagnetic particles in the host material. The particles with a positive susceptibility (paramagnetic) are attracted toward an increasing magnetic field gradient and can be extracted from particles with a negative susceptibility (diamagnetic), which react in the opposite direction, moving away from the areas of high field gradients. Table 1 lists several contaminants and host materials and indicates the magnetic susceptibility of each. The extracted paramagnetic contaminants are flushed from the matrix 
fibers when the magnetic field is reduced to zero or when the matrix canister is removed from the magnetic field. The actinide-containing concentrate can be processed for disposal.

Figure 1. Schematic diagram of High Gradient Magnetic Separation.

Because only a fraction of the original bulk requires disposal, significant cost savings can be achieved.

Table 1. Volume Magnetic Susceptibility of Selected Compounds

\begin{tabular}{|c|c|}
\hline Compound/Element & Susceptibility $\times 10^{6}(\mathrm{SI})$ \\
\hline FeO & 7178 \\
\hline $\mathrm{Fe}_{2} \mathrm{O}_{3}$ & 1479 \\
\hline 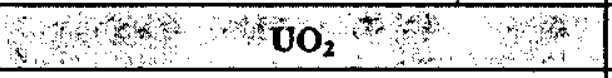 & 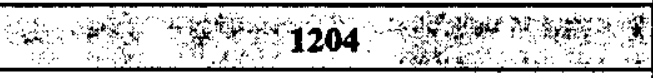 \\
\hline $\mathrm{Cr}_{2} \mathrm{O}_{3}$ & 844 \\
\hline Ant Am & 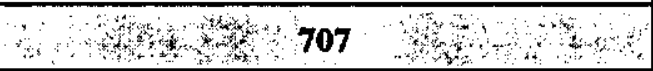 \\
\hline 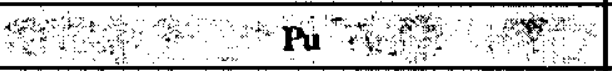 & 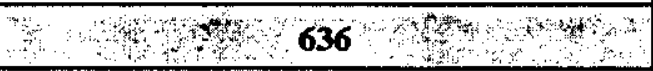 \\
\hline W & H, \\
\hline 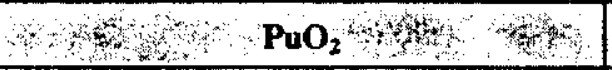 & 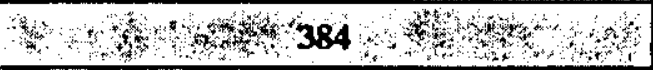 \\
\hline 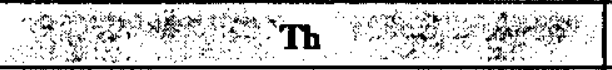 & 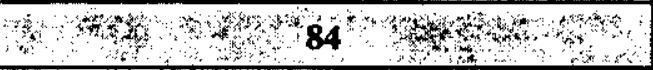 \\
\hline 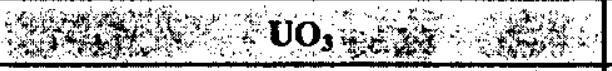 & 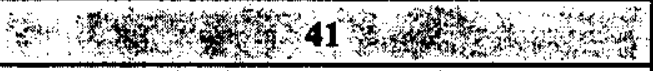 \\
\hline 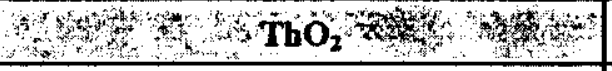 & 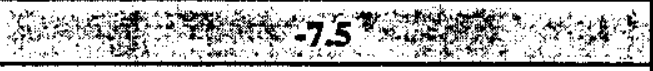 \\
\hline $\mathrm{ZrO}_{2}$ & $\begin{array}{r}-8.0 \\
\end{array}$ \\
\hline $\mathbf{H}_{\mathbf{2}} \mathbf{O}$ & -9.0 \\
\hline $\mathrm{MgO}$ & -11.4 \\
\hline $\mathrm{CaCO}_{3}$ & -13.0 \\
\hline $\mathrm{SiO}_{2}$ & -13.6 \\
\hline Graphite & -14.0 \\
\hline $\mathbf{A l}_{\mathbf{2}} \mathbf{O}_{\mathbf{3}}$ & -18.0 \\
\hline
\end{tabular}




\section{EXPERIMENTAL}

The production of both high magnetic fields ( $>4$ tesla) and large field gradients using superconducting magnet technology now makes it possible to separate small $(>0.1 \mu \mathrm{m})$ paramagnetic particles. Our current HGMS equipment includes one conventional-coil separator and three superconducting high gradient magnetic separators. The conventional coil (one inch bore diameter) and one three inch bore superconducting magnet are installed on a vent hood in the plutonium facility at Los Alamos. This treatability lab is used to handle low-level radioactive samples such as contaminated soils and uranium and plutonium spiked experiments. A second three inch bore superconducting magnet is currently installed at the Los Alamos waste treatment facility where it is being used for experiments with applications of HGMS to waste water treatment. This magnet will soon be moved and interfaced with a glove box in the plutonium facility to investigate applications of HGMS to plutonium chemical processing residues. Finally, a six-inch bore superconducting magnet is being used in a non-radioactive area for non-radioactive and surrogate tests and for prototype development for soil decontamination applications through the CRADA.

The conventional coil magnet is a Pacific Electric Motor Co. crossfield electromagnet with a maximum field intensity of 2.0 tesla. All three superconducting magnets were built by Cryomagnetics, Inc. with maximum field strengths of 8 tesla. The field is axial with respect to the flow through the matrix.

Feed samples, effluents and backflushes are collected and analyzed for each HGMS experiment. Samples are analyzed for uranium or plutonium concentration using alpha spectroscopy (Controls for Environmental Pollution, Santa Fe, NM), gamma spectroscopy (LESAT, Las Vegas, NV) and Instrumental Neutron Activation Analysis, INAA (Activation Laboratories, LTD, Ancaster, Ontario, Canada). HGMS experiments are conducted using both the conventional and superconducting magnets, with magnetic fields orientations both parallel and perpendicular to the slurry flow.

\section{HIGH GRADIENT MAGNETIC SEPARATION ANALYTICAL MODEL}

More than ten variables independently affect the HGMS process (vida infra.); an analytical model for the process was needed to select appropriate bench-scale experiments and to effectively analyze the resulting data. In addition, a validated analytical model supports prototype design and process scaleup. The behavior of the paramagnetic particles as they interact with the magnetized matrix has been investigated through modeling studies in the past. ${ }^{2-8}$ Areas investigated include the dynamic effect of particle trajectories in homogeneous materials, the influence of particle build-up on the matrix elements, and the effects of particles on the flow field. These studies, though requiring simplifying assumptions, identify appropriate independent variables that form the basis for this investigation.

The matrix materials currently used for HGMS are inhomogeneous and have a complex

cross section. In addition, the paramagnetic particles are nonspherical and include a range of particle sizes. All of these factors preclude precise analytical treatment. If the particles are physically liberated from the host material and are not electrically charged, the principle forces goveming their behavior are magnetic, viscous, and gravitational.

The performance of the magnetic separator is modeled using a static force balance on an individual paramagnetic particle in the immediate vicinity of a matrix element, as shown in Figure. 2. The model assumes that if the magnetic capture forces are greater than the 
competing viscous drag and gravity forces, the particle is captured and removed from the flow stream.

Figure 2. Force balance on a paramagnetic particle in the vicinity of a matrix element.

We propose a rate model for this process that depends on a separation coefficient, which we define in terms of a capture cross section and a potential function defined by the force balance on the particle. A series of tests was performed to evaluate separator performance as a function of the independent variables in the separation process. The results were used to determine the separation coefficient in the proposed rate model and were correlated using physically meaningful, dimensionless groups.

We assume that there exists for each matrix element a capture height, wherein each magnetic particle entering the window defined by the capture height and the matrix element diameter will be captured by the matrix element. We then define a capture cross section for a matrix element to be the ratio of the capture height to the matrix element diameter, as shown in Figure 3. The separation coefficient is related to the capture cross section, and if the capture cross section is known, the separation efficiency can be calculated.

Figure 3. The matrix capture cross section defined as the ratio of capture height to matrix element diameter.

\section{HIGH GRADIENT MAGNETIC SEPARATION DATA CORRELATION}

A comprehensive series of experiments was performed to determine the capture cross section as a function of the independent variables. Table 2 lists the variables investigated and their range. For convenience, the list has been divided into material characteristics and separator parameters. A total of 120 experiments were conducted; 76 involved water/contaminant mixtures and 44 involved water/soil/contaminant mixtures. The capture cross section 1 for each test was based on the measured feed and effluent concentrations, the particle force balance, the matrix geometry, and the contaminant particle size.

The capture cross section is significantly less than 1.0 , which implies that particles are swept around the matrix elements by the fluid flow even if the particles enter the region defined by the projected frontal area of the matrix element. In addition, the capture cross 
section is proportional to the magnetic force and the contaminant particle diameter and inversely proportional to the matrix element diameter and the matrix element spacing. These results are consistent with our observations. The cross section 1 is inversely proportional to the superficial velocity, which is the ratio of the separator length and the slurry residence time in the matrix. Intuitively, one expects to have to maximize both the separator length and the matrix residence time for optimum performance; however, only their ratio has to be considered, and this fact makes superficial velocity the more fundamental parameter.

Table 2. Variables in Separator Performance.

\begin{tabular}{c|c}
\hline MATERIAL CHARACTERISTICS & SEPARATOR PARAMETERS \\
\hline Particle Size: Solids and Impurity & Matrix Element Size and Spacing \\
Impurity Concentration & Matrix MaterlaVOrientation \\
Solids Concentration & Magnetic Field Strength \\
Solids Type & Matrix Residence Time/Flow Velocity \\
Magnetic Susceptibility & Matrix Volume/Temperature \\
& Surfactant, pH
\end{tabular}

\section{RESULTS AND DISCUSSION}

We have completed a comprehensive series of HGMS experiments with nonradioactive surrogates, as discussed above, and have progressed to tests with radioactive material. The results to date are very promising and are summarized below.

\section{Contaminated Soils}

After completion of the work with surrogate systems, work on radioactive samples was started. One of the biggest contamination problems within the DOE Defense Complex is contaminated soils. To address the feasibility of using HGMS for these problems, preliminary tests using uranium and plutonium spiked systems were investigated. Much of the original radioactive work was performed using the 2.0 tesla electromagnet.

Uranium. Figure 4 shows the results of an HGMS experiment to extract $\mathrm{UO}_{3}$ from water. The efficiency of separation was expected to be only approximately $70 \%$, based on model calculations, due to the low magnetic susceptibility of $\mathrm{UO}_{3}\left(\chi \mathrm{vol}=41 \times 10^{-6}(\mathrm{SI})\right.$ ). The results show much better separation than expected. The $\mathrm{UO}_{3}$ had an equivalent Stoke's diameter of $2-5 \mu \mathrm{m}$ and the experiment was conducted at 2.0 tesla at pHs of 7 and 12 . One other variable that was investigated was the addition of magnetite to the $\mathrm{UO}_{3}$ slurry. The use of magnetite as a plutonium and americium waste treatment process was reported by Kochen and Navratil in 1987. ${ }^{9}$ The process works by adsorption of the actinide to the ferrite surface, followed by magnetic separation. Magnetite is ferromagnetic and is easily extracted using magnetic separation. 
Our results show that with only one pass through the magnetic separator at 2.0 tesla

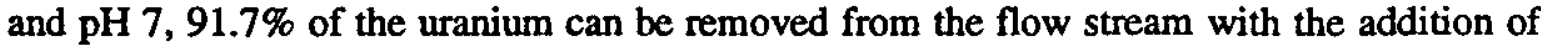
magnetite. Also encouraging was that even without the addition of magnetite, $>85 \%$ of the uranium was removed on two passes through the separator at $\mathrm{pH} 7$. These results were very encouraging as we anticipated moving toward experiments with authentic uranium contaminated soils.

Figure 4. Extraction of $\mathrm{UO}_{3}$ from Water. Variables: $\mathrm{pH}, \mathrm{Fe}_{3} \mathrm{O}_{4}$; Field Strength = 2 tesla; $\mathrm{UO}_{3}$ Particle Size $=2.5 \mu \mathrm{m}$.

$\mathrm{PuO}_{2}$ Spiked Soils. Many sets of experiments have been performed on $\mathrm{PuO}_{2}$-spiked clay and $\mathrm{SiO}_{2}$ slurries. Variables that been investigated include $\mathrm{pH}$, soil particle size, $\mathrm{PuO}_{2}$ particle size, and field strength. In general, for $2-5 \mu \mathrm{m} \mathrm{PuO}_{2}$ particles, $>90 \%$ of the plutonium can be removed from the influent flow stream during an HGMS experiment. This number is calculated as the difference in the influent activity and the effluent activity (Ci$\mathrm{Co} / \mathrm{Ci})(100)$. Typically, final plutonium concentrations are between 20 and $80 \mathrm{pCi} / \mathrm{g}$.

Figure 5 shows the results of a typical HGMS experiment to extract $\mathrm{PuO}_{2}$ from $\mathrm{SiO}_{2}$. A 10 weight percent slurry was pumped through the separator at two different pH values. From the graph it is clear that there is little difference in the separation efficiency for removal of $\mathrm{PuO}_{2}$ from $\mathrm{SiO}_{2}$ at $\mathrm{pH} 7$ and $\mathrm{pH} 10$. About $98.5 \%$ of the plutonium activity is removed from the $\mathrm{PuO}_{2}$-spiked mixture at both $\mathrm{pH} 7$ and $\mathrm{pH} 10$. Similar results were seen for $\mathrm{PuO}_{2}$-spiked clay slurries, however we observed ca. $10-15 \%$ better extraction of the $\mathrm{PuO}_{2}$ at $\mathrm{pH} 10$ than at $\mathrm{pH} 7$.

Figure 5. HGMS Extraction of $\mathrm{PuO}_{2}$ from $\mathrm{SiO}_{2}$ : Effect of $\mathrm{pH}$. Field Strength $=6.5$ tesla; $\mathrm{PuO}_{2} \mathrm{Size}=2$ $5 \mathrm{~mm} ; \mathrm{SiO}_{2}$ size $=10-45 \mathrm{~mm} ; 10 \%$ solids; $0.2 \%$ Hexametaphosphate. 
The variable that had the most effect on the extraction of $\mathrm{PuO}_{2}$ from $\mathrm{SiO}_{2}$ was the solids particle size. When $10-45 \mu \mathrm{m} \mathrm{SiO}_{2}$ was used the extraction efficiency was only about $85 \%$. With the $<10 \mu \mathrm{m} \mathrm{SiO} 2$ the extraction efficiency was $>95 \%$. This is probably due to the bigger $\mathrm{SiO}_{2}$ particles knocking the smaller $\mathrm{PuO}_{2}$ particles off of the matrix. This was not observed in the clay experiments because typically the clay has very few particles $>20$ $\mu \mathrm{m}$ in size.

Authentic Soils. At the Fernald Environmental Management Project (FEMP) near Cincinnati, Ohio, there are an estimated $2,000,000$ to $4,000,000 \mathrm{~m}^{3}$ of soil contaminated with uranium. The source of the uranium contamination is from the deposition of airborne particulates from incinerator stacks, aqueous uranium wastes from chemical processing, and solid uranium product spills. The target clean-up for the soils is $30 \mathrm{ppm}$. Current technologies for remediation of the soil include 1) excavation and transportation of the soil to a repository, 2) immobilization of the uranium in place, 3) physical separation and removal of the highly contaminated soil fractions from the balance of the soil, and 4) soil washing. The incinerator areas, as mentioned above contain soil with uranium contamination in the form of particulates. This makes HGMS a strong candidate for partitioning of the uranium from the soil.

Figure 6 shows the results of an HGMS test run on an incinerator area soil from Fernald. The soil was dry sieved to $<53 \mu \mathrm{m}$ and a 10 weight $\%$ slurry was run through the magnetic separator at 2.0 tesla and at three different $\mathrm{pH}$ values. The incinerator area soil contains about $500 \mathrm{ppm}$ uranium. Spectroscopic characterization indicates that the uranium is ca. $75 \% \mathrm{U}(\mathrm{VI})$ and $25 \% \mathrm{U}(\mathrm{IV})$.

Figure 6. HGMS of Uranium from Fernald Soil. Field Strength = 2 tesla; $10 \%$ solids; $0.2 \%$ Hexametaphosphate.

From the data it is clear that the separation did not work well at $\mathrm{pH} 10$. However, $\mathrm{pH}$ 8 and $\mathrm{pH} 4$ both show promising results. At $\mathrm{pH} 4 \mathrm{ca}$. $58 \%$ of the uranium was concentrated in $14 \%$ of the bulk mass. At pH $8 \mathrm{ca}$. $47 \%$ of the uranium was concentrated in only $3 \%$ of the bulk mass. Both of these results represent reasonable separation efficiencies for only one pass through the separator and at only 2.0 tesla field strength. However, in neither test run were we able to reach the $52 \mathrm{ppm}$ uranium target. A second series of tests is planned with test variables of $\mathrm{pH}$ and field strength. Also planned are experiments involving reducing agents. If the U(VI), which has a low magnetic susceptibility, can be reduced to $\mathrm{U}(\mathrm{IV}),\left(\chi>1000 \times 10^{-6}(\mathrm{SI})\right)$ we have a much better chance at removing it by magnetic separation. Also planned are tests with magnetite seeding due to the success as had employing this technique with $\mathrm{UO}_{3}$ in water. 
The second DOE soil we have tested using HGMS is from the Nevada Test Site. The soil is a residue from Lockheed Environmental Systems \& Technologies. The residue we received were the fines $(<100 \mu \mathrm{m})$ from the soil that had been processed through a centrifugal jig and a screw classifier. Again, the residue was sieved to $<53 \mu \mathrm{m}$ and two passes of a 10 weight \% slurry were passed through the magnetic separator at $\mathrm{pH} 8$ and $\mathrm{pH}$ 10. The results from the first pass are shown in Figure 7. The first pass was performed at only 0.25 Tesla. At both $\mathrm{pH}$ values $83-84 \%$ of the plutonium was removed from the flow stream. However, ca. $30 \%$ of the soil mass was also caught in the separator.

Figure 7. HMGS of plutonium from NTS Residue: LESAT Thickener Underflow Residue. Effect of $\mathrm{pH}$. Field Strength: Pass $1=0.25$ tesla; $10 \%$ solids; $0.2 \%$ Hexametaphosphate.

On pass 2 at 0.5 tesla another $24 \%$ and $32 \%$ of the mass was collected at $\mathrm{pH} 8$ and $\mathrm{pH}$ 10 , respectively. These results indicate that the NTS residue is highly magnetic and the activity is probably tied up with the magnetic minerals. We are exploring other pretreatment options to try and liberate the plutonium from the soil. A second series of tests has been scheduled.

Soil Results Summary. We have conducted more than 100 HGMS experiments on paramagnetic surrogate materials in water and simulated soils. We have shown that $>95 \%$ of the paramagnetic contaminant can be extracted from the surrogates. HGMS tests have begun on authentic contaminated soils. Preliminary tests have been performed on Fernald soil and NTS residue. Information from these tests is being used to determine test parameters and pretreatment steps. Future soils to be investigated include samples from Rocky Flats Plant, Johnston Atoll, Hanford, INEL, Mound and Los Alamos.

\section{Waste Water Treatment}

High Gradient Magnetic Separation (HGMS) is also being investigated for applications to waste water treatment. Los Alamos National Laboratory Waste Treatment Facility has an average annual influent of 20 million liters with an average gross alpha activity of $70 \mathrm{nCi} / \mathrm{L}$ from isotopes of plutonium and americium. ${ }^{10}$ The contaminants are in the form of particulates, colloids, polymerized colloids and dissolved ions. Another important characteristic of the waste is that most of the activity is associated with particles in the $1-20 \mu \mathrm{m}$ size range.

Current DOE regulations for the radioactive levels in the effluent allow $30 \mathrm{pCi} / \mathrm{L}$ gross alpha for plutonium and americium combined. Current treatment at the waste facility results 
in an effluent activity of $c a .50 \mathrm{pCi} / \mathrm{L}$. Another major concern with the current treatment process is the large volume of low level radioactive sludge that is generated. Annually, 200 55 -gal. drums of sludge are produced in the process. New technologies are being sought that can achieve the desired effluent activity levels while producing a minimum of secondary sludge waste. Because the contaminants are in the form of particulates or colloids in the 1$20 \mu \mathrm{m}$ size range, HGMS is a strong candidate to address the problems at the LANL Waste Treatment Facility. HGMS also has the advantage of producing a minimum of secondary waste.

One of the 3-inch bore, 8 tesla superconducting magnets was set up at the waste treatment facility to perform treatability tests on plant influents. The first test was performed on influent that had been in a holding tank for $c a$. six months. The $\mathrm{pH}$ was adjusted to $\mathrm{pH} 8$. Three different concentrations of magnetite were added to the influent to aid in the separator performance and address the problem of the dissolved ions. The test was performed at a field strength of 7.5 tesla and the results are shown in Figure 8. In each run, over three orders of magnitude of reduction in plutonium activity were achieved. It appears that the addition of magnetite is not necessary to achieve these separation efficiencies. Activity levels below $10 \mathrm{pCi} / \mathrm{L}$ were achieved, well below the $30 \mathrm{pCi} / \mathrm{L}$ required by the DOE, with or without magnetite seeding.

Figure 8. HGMS of LANL Waste Treatment Facility influent. Field Strength $=7.5$ tesla; $\mathrm{pH} 8$

Future HGMS tests are planned on raw waste treatment facility influent, (i.e. influent that has not been stored in a holding tank.) The question has been raised as to whether the influent is changing with time in the holding tank.

\section{CONCLUSIONS AND DEVELOPMENT PLANS}

We have demonstrated that HGMS can be used to concentrate actinides in waste residues and contaminated soils. One of the major benefits of this technology is that it partitions the existing waste volume, creating a low volume, high contaminant concentration component and a high volume, low contaminant concentration component. If the separation efficiency is high, the high volume component can be discarded and the low volume component can be processed further or packaged for disposal. Concentration of the actinides from extraneous materials before further processing can result in more efficient recovery or treatment operations.

We plan to continue to utilize our magnetic separators for surrogate and authentic contaminated soils, residues and waste streams to determine operational parameters. The 
experimental results will continue to be used to develop a performance-based HGMS model. We hope to demonstrate the application of HGMS to the separation of actual residues, waste streams and contaminated soils and to develop HGMS for new applications. Results from the CRADA tests are being used to support LESAT's prototype separator design effort.

\section{REFERENCES}

1. Avens, L.R., Worl, L.A., de Aguero, K.J., Padilla, D.D., Prenger, F.C., Stewart, W.F., Hill, D.D., Tolt, T.L. Proceedings of the Symposium on Waste Management, Tuscon, Arizona, Mar, 1993, p. 787; Worl, L.A., Avens, L.R., Aguero, K.J., Prenger, F.C., Stewart, W.F., Hill, D.D. Proceedings of the Symposium on Waste Management, Tuscon, Arizona, Mar, 1993, p. 1039.

2. Akoto, I.V. IEEE Transactions on Magnetics 1977, 13, 1486.

3. Friedlander, F.J., Takayasu, M., Rettig, J.B., Kentzer, C.P., IEEE Transactions on Magnetics 1978, 14, 1158.

4. Lawson, W.F., Simons, W.H., Treat, R.P., J. Appl. Physics 1977, 48, 3213.

5. Luborsky, F.E., Drummond, B.J. IEEE Transactions on Magnetics 1976, 12, 463.

6. Nesset, J.E., Finch, J.A., Industrial Appl. Mag. Sep., Conference Proceedings 1978, 188.

7. Stekly, Z.J.J., Minervini, J.V. IEEE Transactions on Magnetics 1976, 12, 474.

8. Watson, J.H.P. J. Appl. Physics 1973, 44, 4209.

9. Kochen, R.L., Navratil, J.Dl. Lanthanide and Actinide Research 1987, 9, and references therein.

10. Covey, J.R., Midkiff, W.S., Cadena, F. Industrial Waste Conference, 47th Annual Purdue University, May, 1992.

\section{DISCLAIMER}

\footnotetext{
This report was prepared as an account of work sponsored by an agency of the United States Government. Neither the United States Government nor any agency thereof, nor any of their employees, makes any warranty, express or implied, or assumes any legal liability or responsibility for the accuracy, completeness, or usefulness of any information, apparatus, product, or process disclosed, or represents that its use would not infringe privately owned rights. Reference herein to any specific commercial product, process, or service by trade name, trademark, manufacturer, or otherwise does not necessarily constitute or imply its endorsement, recommendation, or favoring by the United States Government or any agency thereof. The views and opinions of authors expressed herein do not necessarily state or reflect those of the United States Government or any agency thereof.
} 


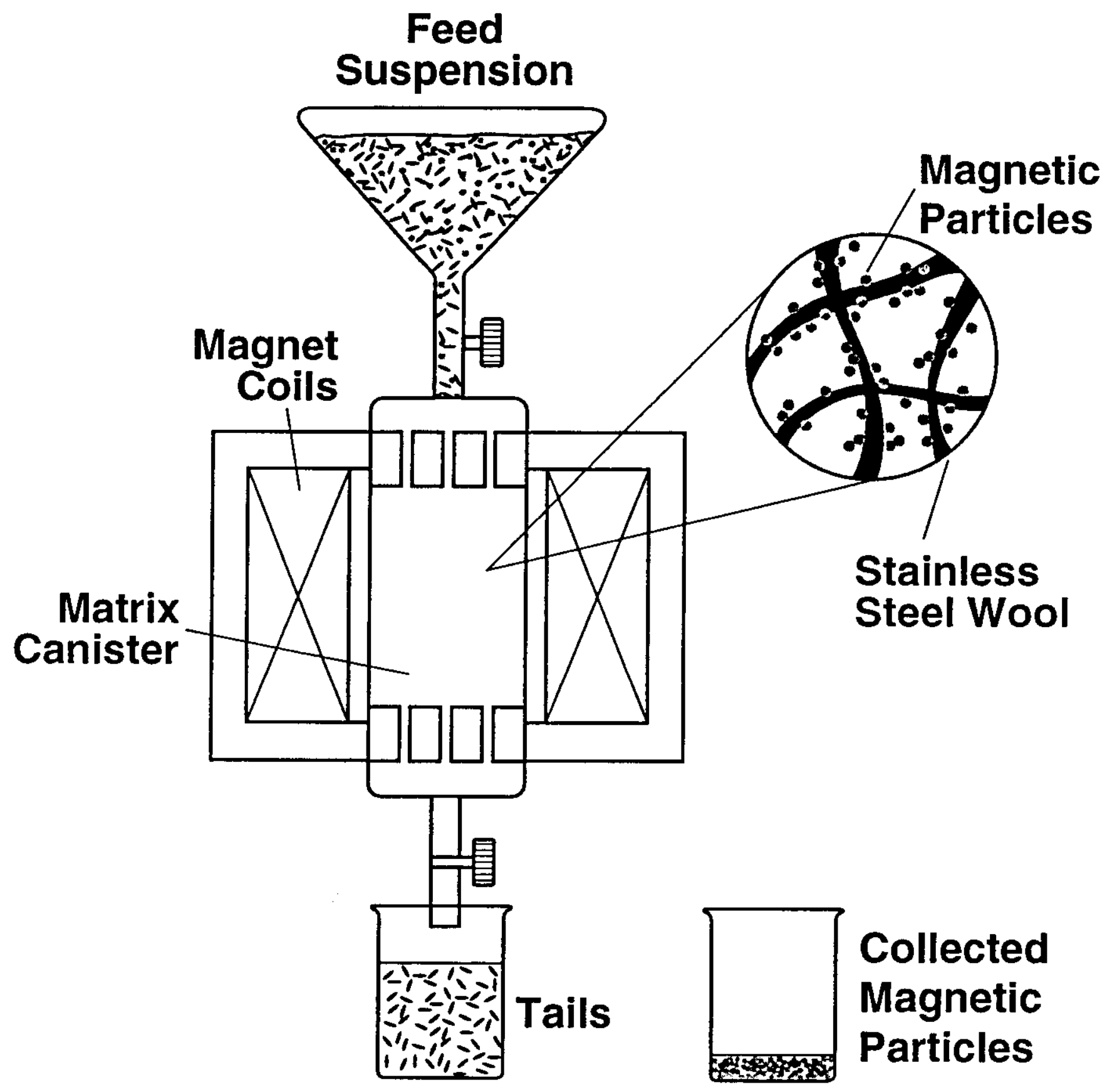




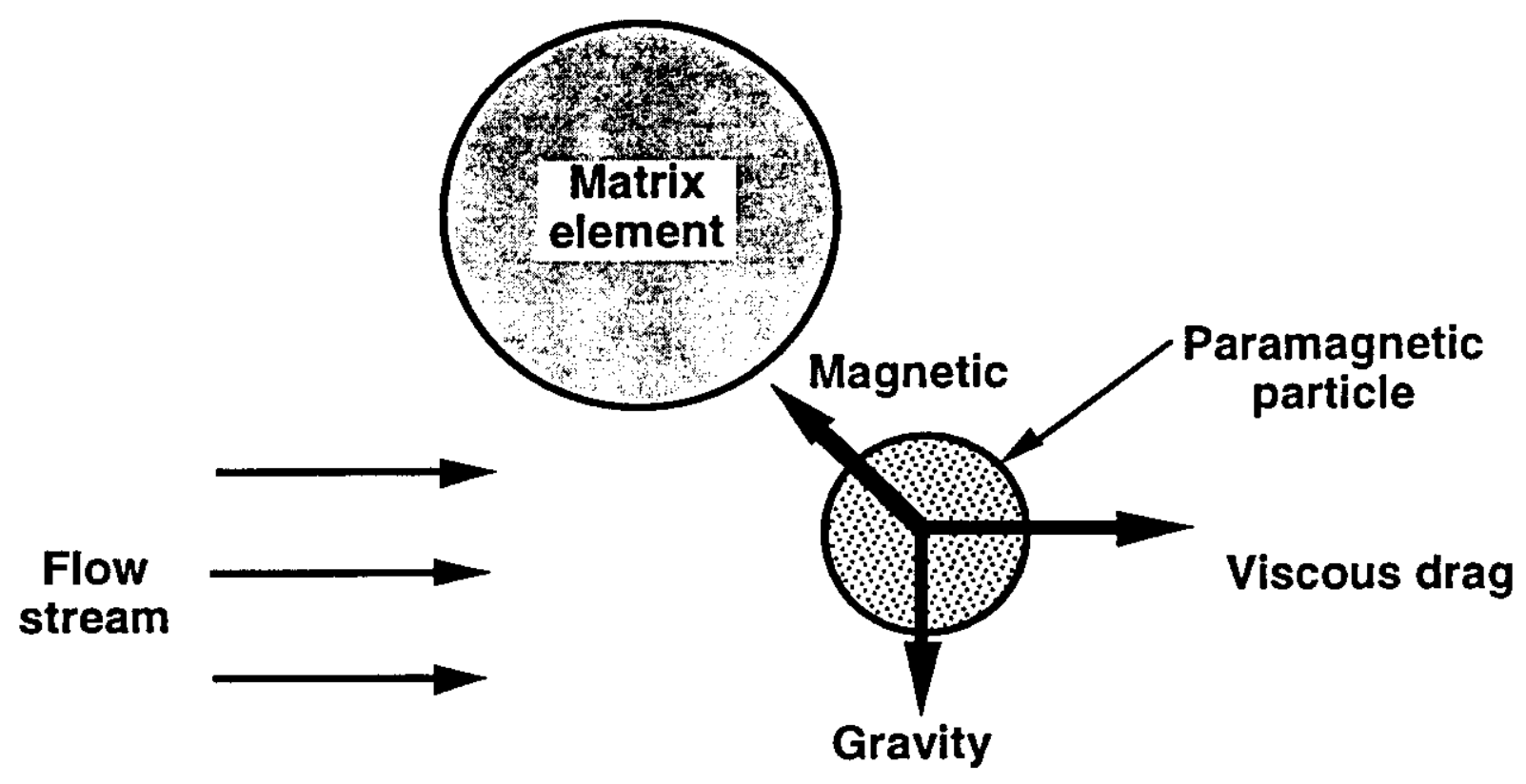




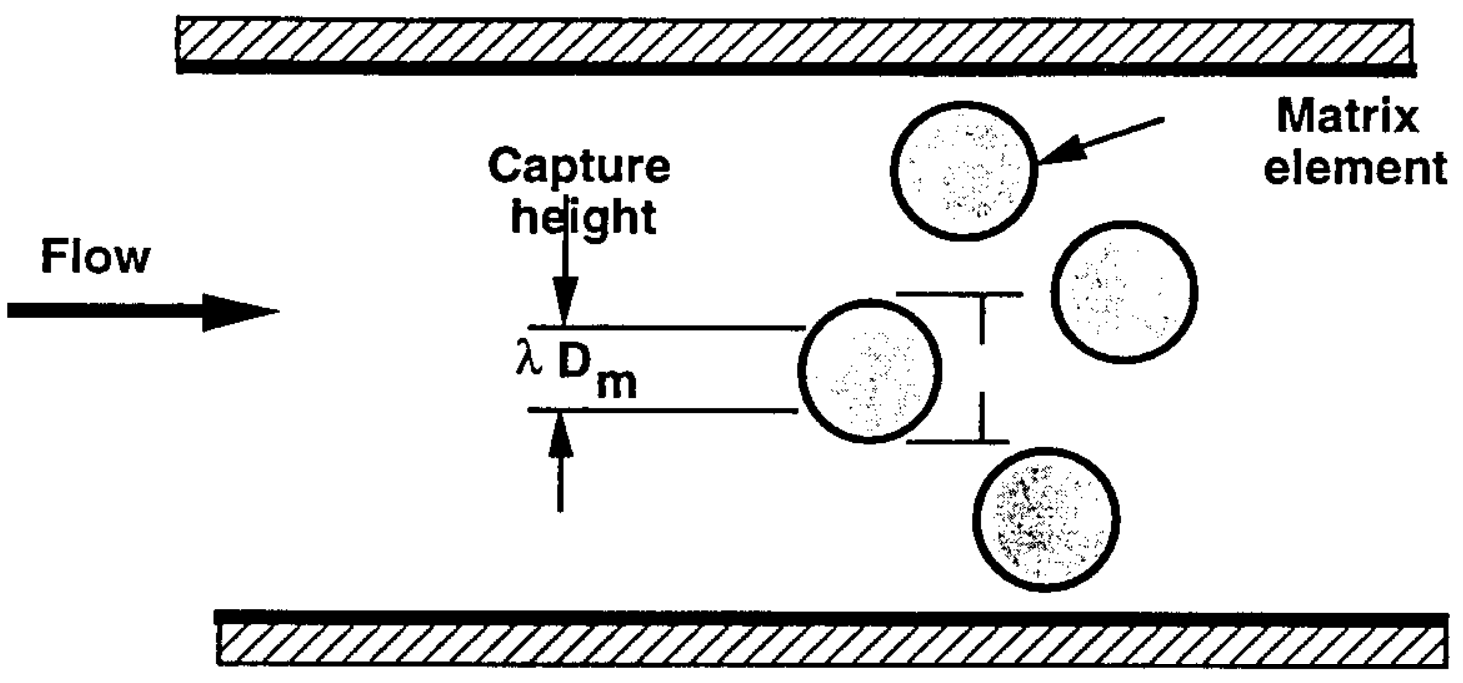

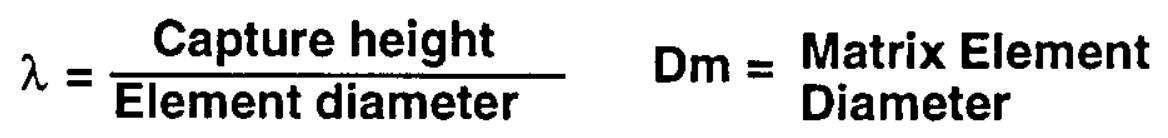




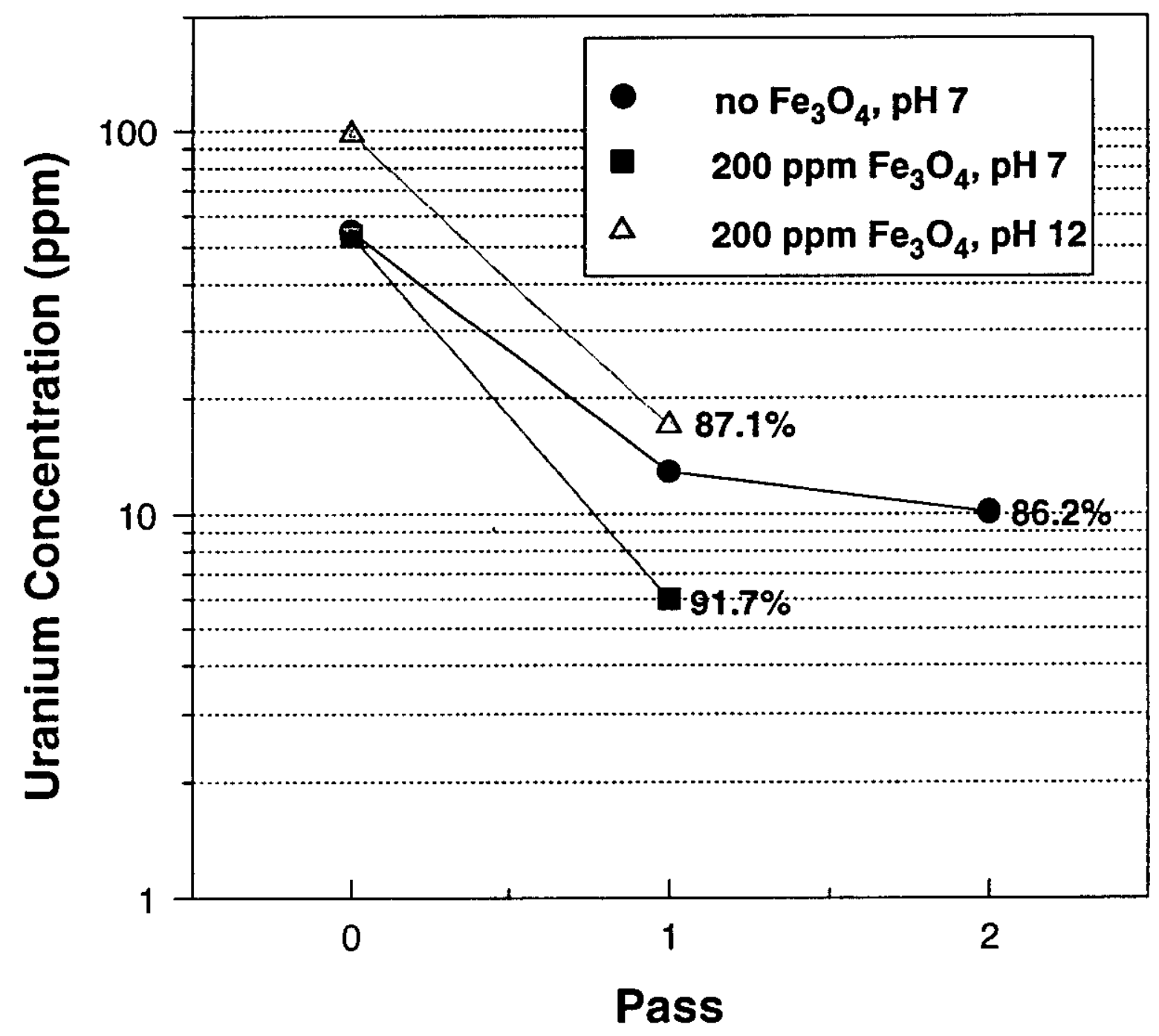




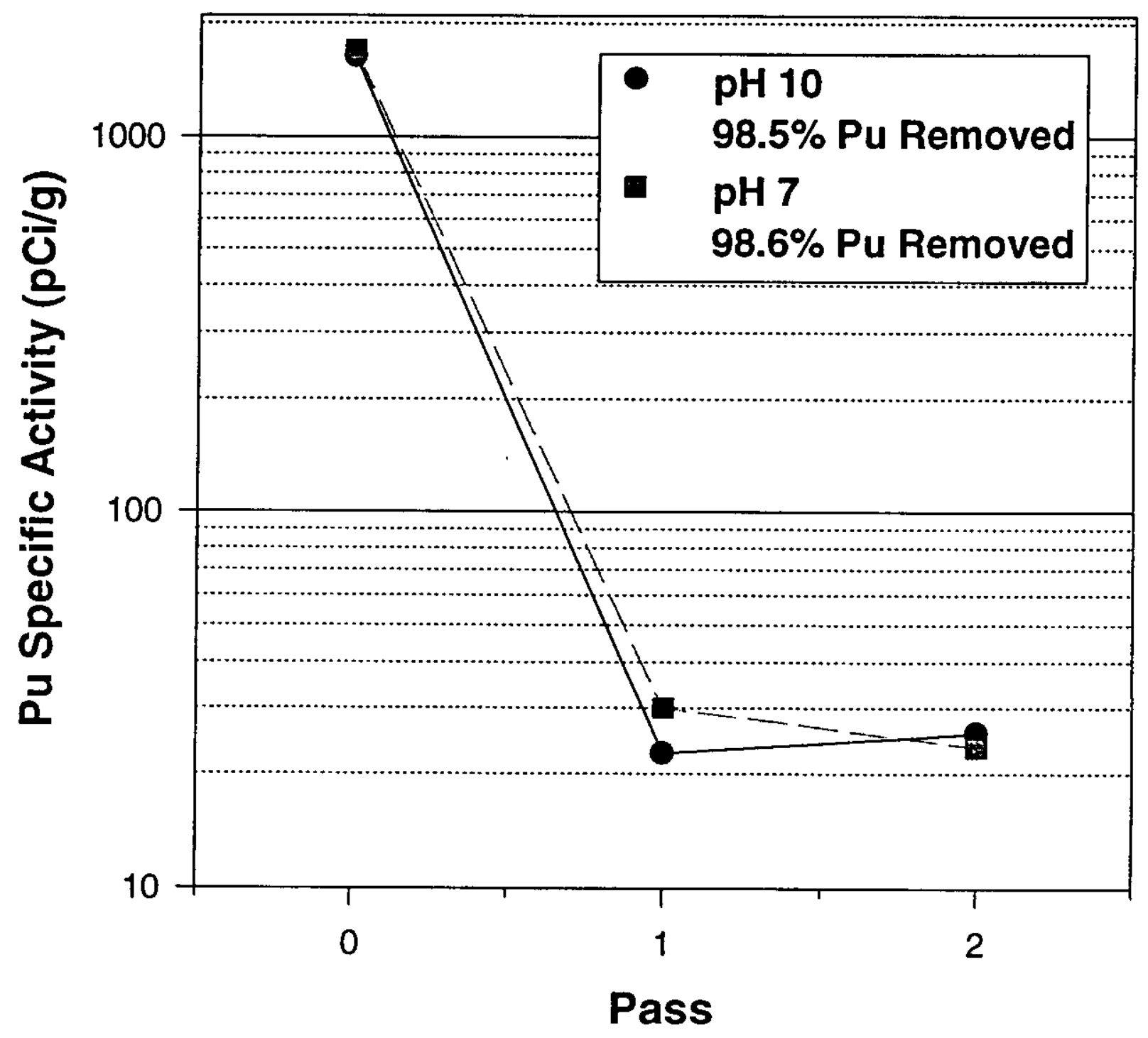




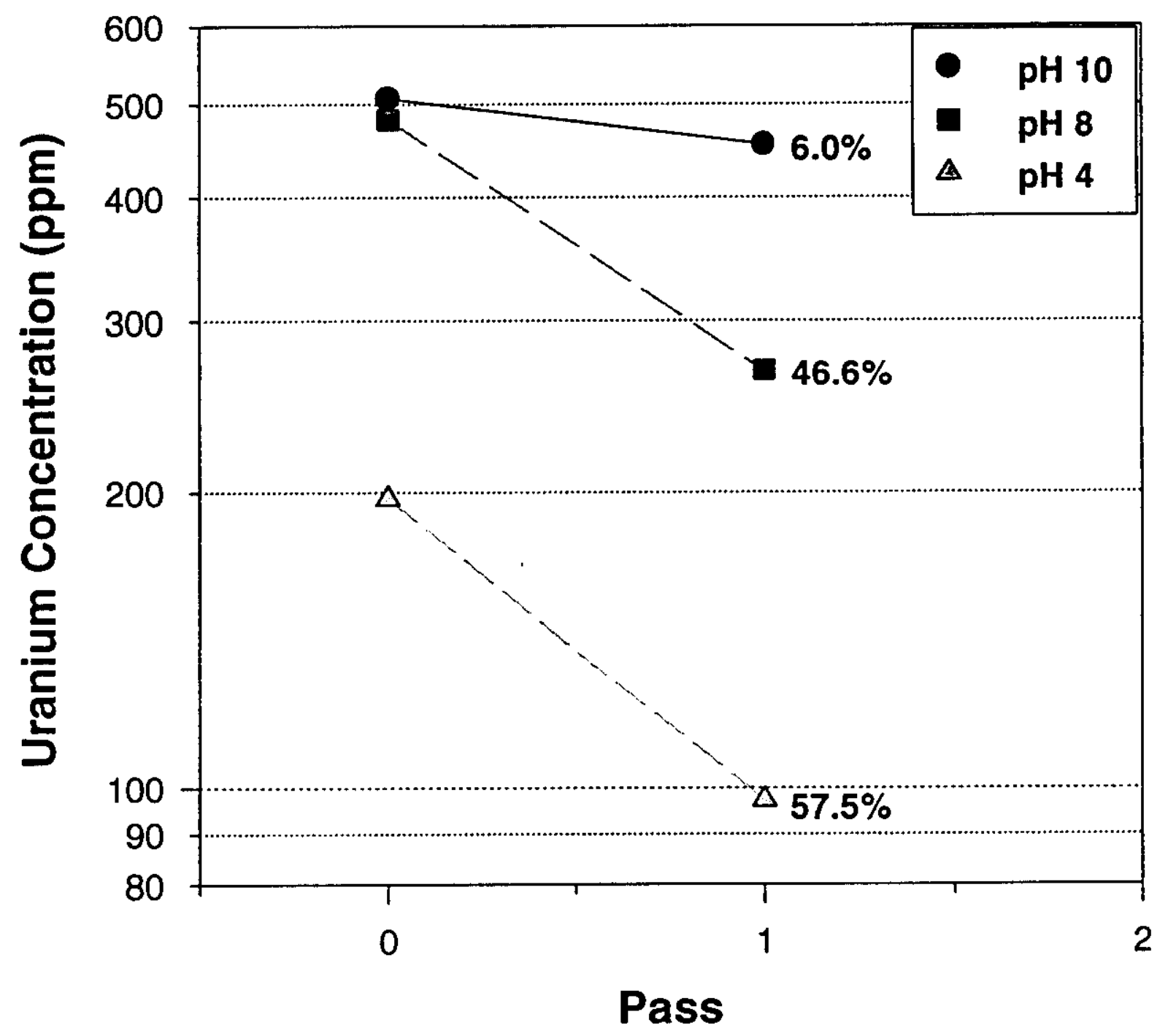




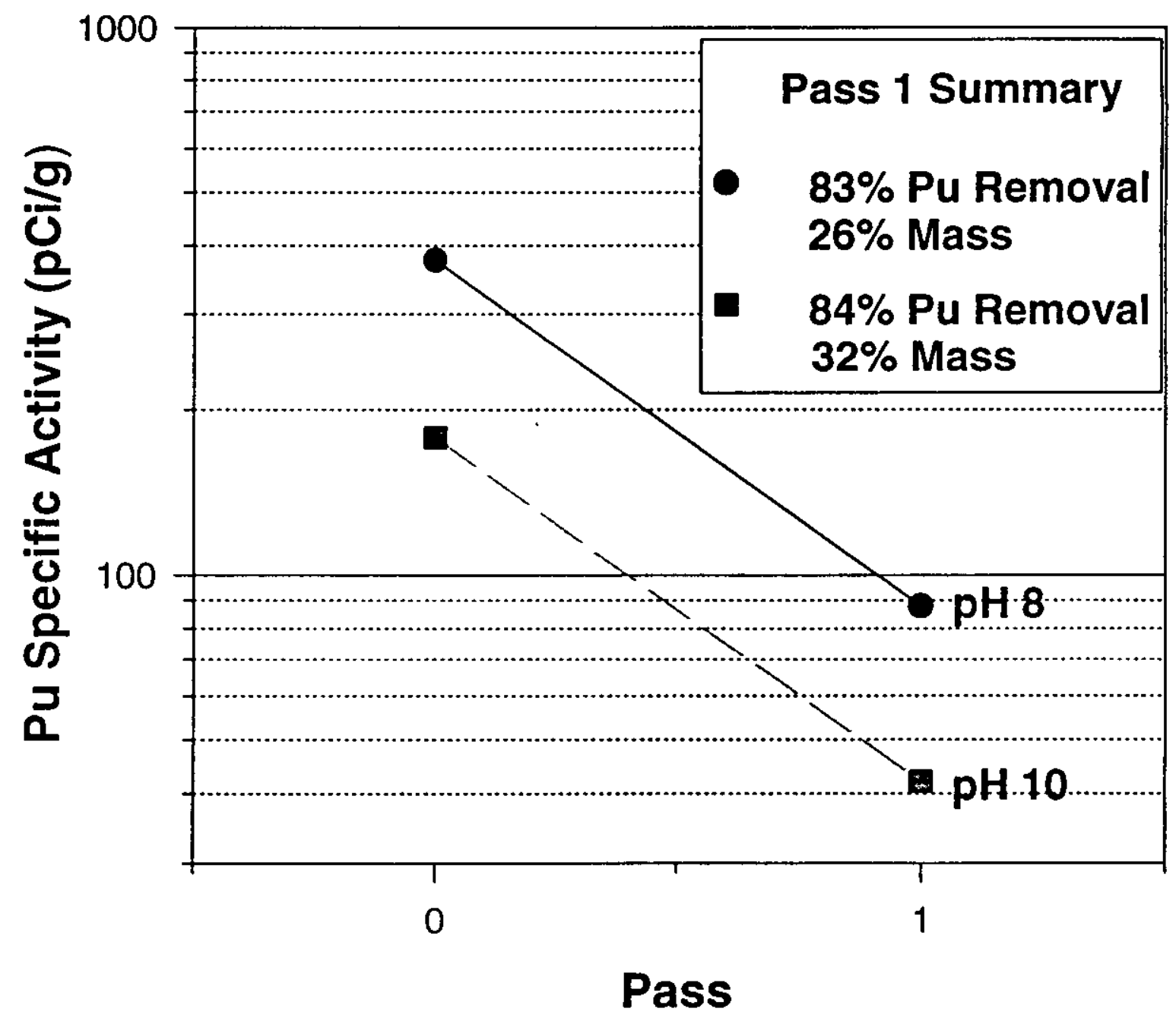




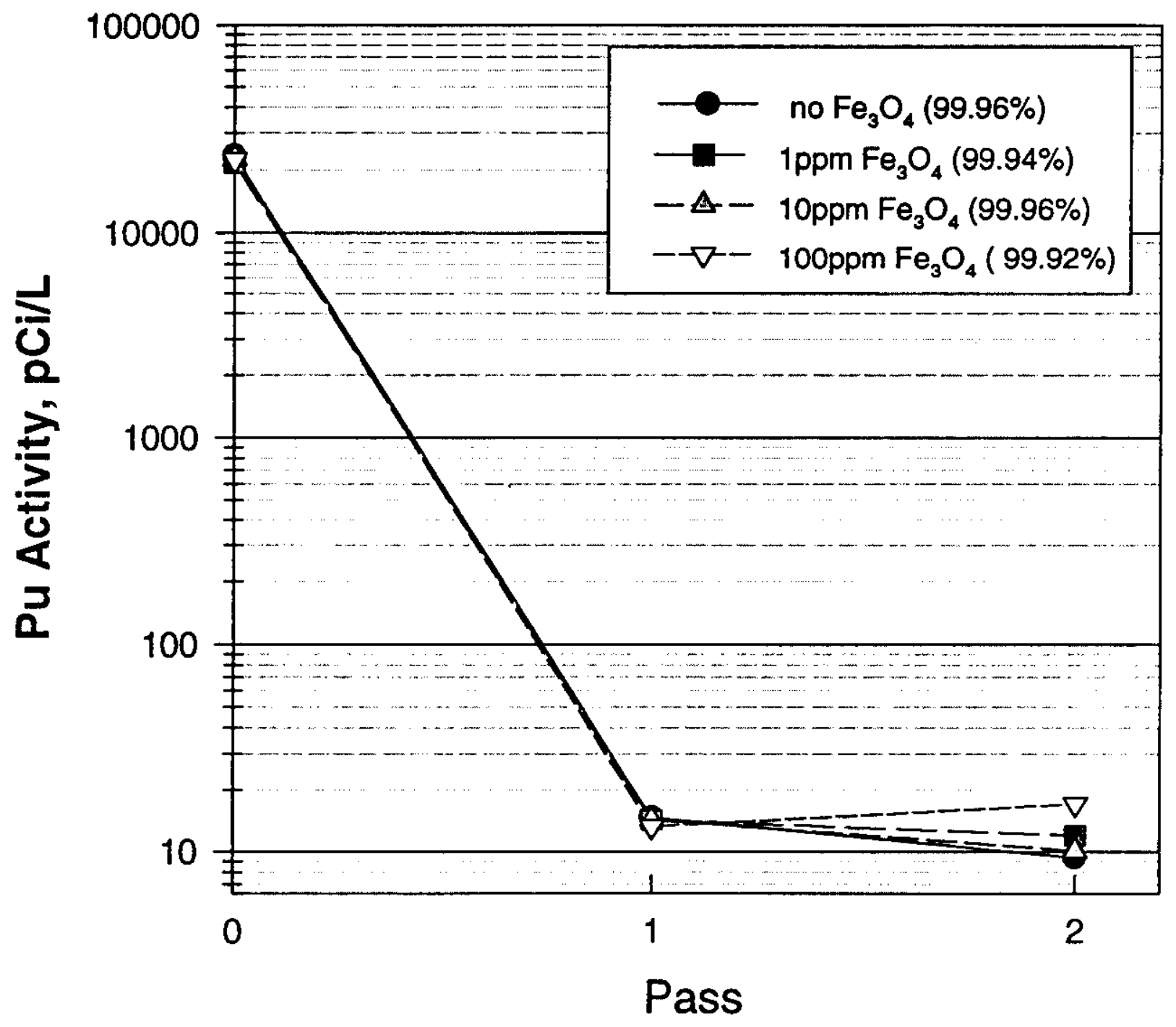

